\title{
Integración y desempeño de los órganos públicos locales electorales en las elecciones subnacionales de 2015 en México
}

\author{
Local Electoral Management Bodies' \\ Performance in the Subnational Elections \\ in Mexico in 2015
}

\section{Nicolás Loza* Irma Méndez**}

\section{Sumario:}

I. Introducción.

II. La reforma electoral de 2014.

III. Integración de los órganos públicos locales electorales.

IV. El desempeño de los órganos públicos locales electorales: independencia, imparcialidad y procedimientos.

V. Índice de integridad electoral y selección de consejeros electorales locales.

VI. Conclusiones.

VII. Fuentes consultadas.

* Profesor e investigador en la Flacso México; miembro del SNI.

** Profesora e investigadora en la Flacso México; miembro del SNI. 
Esta revista forma parte del acervo de la Biblioteca Jurídica Virtual del Instituto de Investigaciones Jurídicas de la UNAM

\section{Resumen:}

En este artículo presentamos evidencia sobre el magro desempeño en imparcialidad, y los débiles resultados positivos en independencia y profesionalismo, de los órganos públicos locales electorales en las elecciones locales de 2015 en México. A su vez, encontramos una relación entre la ocurrencia de excepciones y brechas en las evaluaciones que llevaron a la selección de los consejeros electorales de los órganos públicos locales electorales, y la menor integridad electoral en cada entidad.

\section{Abstract:}

In this paper we present evidence on the poor performance and the weak independence of the new local electoral management bodies in Mexico in 2015 local elections. After analyzing the recruitment process to integrate such bodies we also found a relationship between the occurrence of exceptions and gaps in assessments that led to the selection of electoral counselors and the lower electoral integrity in each state..

Palabras clave: elecciones subnacionales, elecciones en México en 2015, administración electoral, integridad electoral.

Keywords: subnational elections, 2015 local elections, electoral integrity, electoral management bodies, Mexican political parties. 


\section{Introducción}

Las reglas electorales son dinámicas en gran parte de las democracias nuevas y consolidadas, y sus cambios son parte del juego político democrático. Las propuestas de reforma son tan comunes, según Shaun Bowler y Todd Donovan, que revelan algunas características persistentes de toda política, como la imposición de costos a ciertos actores y beneficios a otros, el papel de la sociedad en el apoyo o rechazo a las reformas, las altas expectativas que generan, y de particular relevancia, los limitados efectos que producen. ${ }^{1}$ Parece que las expectativas son, en la mayoría de los casos, excesivas, cuando las reformas electorales al final modifican muy poco la realidad política de un país.

La reforma electoral en México de 2014 modificó radicalmente el proceso de integración y funcionamiento de los órganos electorales locales, llamados organismos públicos locales electorales (OPLE), a partir de la introducción de un procedimiento de selección de sus consejos generales, definido y ejecutado por el órgano electoral federal: el Instituto Nacional Electoral (INE). Pese a la relevancia del cambio, poco se sabe de los resultados de la transformación en el diseño institucional electoral a nivel subnacional. ¿En qué medida el cambio en el proceso de selección de consejeros dio como resultado que los OPLE fueran independientes, imparciales y profesionales? ¿Qué tan íntegras fueron las elecciones subnacionales de 2015 ? ¿Se relaciona la integridad electoral subnacional con la calidad de los nuevos OPLE?

Con el propósito de contribuir al conocimiento de los problemas antes formulados, este artículo analiza la independencia, imparcialidad y profesionalismo de los nuevos OPLE, así como la posible relación de la calidad en el proceso de integración de los consejos generales de los OPLE en la integridad en los 17 comicios locales de 2015. Con los indicadores utilizados, encontramos avances marginales en términos de la independencia, debido a las primeras fases de una selección filtrada por la demostración de competencias, asociada a fases posteriores en que el mérito también intervino sin desprenderse de consideraciones políticopartidarias. También ubicamos cambios positivos en el profesionalismo, con estándares establecidos a nivel nacional, pero los resultados son menos alentadores en términos de la imparcialidad de los OPLE encargados

1 Bowler, Shaun y Donovan, Todd, The Limits of Electoral Reform, Oxford, Oxford University Press, 2013, pp. 3 y 4. 
de las elecciones de 2015, pues muestran un partidismo percibido como alto. Finalmente, encontramos una relación entre la ocurrencia de excepciones y brechas (que más adelante explicaremos) en las evaluaciones que llevaron a la integración de los consejos generales de los OPLE, y la menor integridad electoral en cada entidad.

Este artículo está dividido en tres secciones. En la primera se expone el nuevo modelo de administración electoral, los cambios fundamentales incorporados en la nueva Ley General de Instituciones y Procedimientos Electorales (Legipe). En la segunda sección se analiza la integración de los OPLE a partir de la construcción de dos indicadores, uno derivado de las calificaciones obtenidas por los aspirantes a consejeros locales en el examen estandarizado, y otro que agrega la ocurrencia de excepciones y brechas en la utilización de esas notas, al momento de formar los consejos generales. En la tercera sección se analiza el desempeño de los OPLE en las elecciones locales de 2015, a partir del examen de su independencia formal, de lo que dice la ley, así como de su imparcialidad, profesionalismo e integridad en general, con datos del proyecto de integridad electoral (PEI, por sus siglas en inglés) de las elecciones 2015 a nivel subnacional, a los que identificaremos como mediciones del Integrity Project (IP). En la parte final, se examina la relación entre las evaluaciones estandarizadas que obtuvieron los consejos generales de cada estado, la ocurrencia de excepciones y brechas al conformar la máxima autoridad de los OPLE, y la calidad de las elecciones a partir del indicador de integridad electoral.

\section{La reforma electoral de 2014}

La reforma electoral de 2014 forma parte de la larga lista de cambios, en esa materia, de las últimas dos décadas en México. Antes del proceso de democratización, los gobiernos en turno emplearon las reformas electorales como un mecanismo para modular la competencia y el acceso al poder, al establecer una combinación entre normas incluyentes, que generaban condiciones para una mayor participación de partidos o candidatos opositores, y normas restrictivas, que limitaban su acceso a posiciones o instituciones. Además, al menos cada seis años se aprobaba una nueva reforma que cambiaba las reglas del juego, producto de negociaciones entre los distintos grupos de poder al interior del Partido Revolucionario Institucional (PRI). ${ }^{2}$

2 Méndez de Hoyos, Irma, Transición a la democracia en México. Competencia partidista y reformas electorales 1977-2003, México, Fontamara, 2006. 
La transición a la democracia implicó cambios profundos en el contenido y el proceso de negociación de las reformas electorales, aunque se mantuvo su uso extensivo y el modelo "federalista" sobre el cual había descansado el sistema político mexicano. Dicho modelo partía de la separación de los órganos electorales locales y federales. A nivel federal, éstos estaban regulados por la Constitución Política de los Estados Unidos Mexicanos (CPEUM) y por una ley electoral federal, además de otras leyes secundarias. A nivel local, eran regulados por la Constitución de cada una de las entidades federativas y por su ley electoral respectiva. Aunque eran pocos los puntos de contacto y colaboración entre órganos federales y locales, existían muchos conflictos.

En materia de órganos electorales, las reformas a ese sistema, aprobadas por el consenso de gran parte de (o todas) las fuerzas políticas, entre 1990 y 1996 crearon el Instituto Federal Electoral (IFE) y el Tribunal Electoral del Poder Judicial de la Federación (TEPJF), bajo el paradigma de la independencia, la imparcialidad y el profesionalismo. A los cambios a nivel federal siguió una larga cascada de reformas locales que replicaban el patrón federal, al menos al principio, con órganos electorales locales autónomos y no partidistas. Sin embargo, después de una década, el número de reformas políticas locales se multiplicó, y los modelos electorales se diversificaron hasta tener formatos "a modo" bajo el control del gobernador o del Congreso.

El diagnóstico presentado por los partidos políticos en las iniciativas de la reforma de 2014 puso de manifiesto críticas y expectativas partidistas: el Partido Acción Nacional (PAN) fue enfático al sostener que los órganos electorales locales habían sido capturados por parte del gobernador del estado y, por ello, propuso un método diferente de nombramiento de los consejeros electorales locales y la homologación de estándares y procesos entre órganos locales y federales; ${ }^{3}$ por su parte, el Partido de la Revolución Democrática (PRD) buscaba garantizar la imparcialidad de las autoridades electorales y la equidad en las contiendas, ${ }^{4}$ mientras que el PRI centraba su atención en la reforma electoral como parte del Pac-

3 Iniciativa con Aval de Grupo Parlamentario del Partido Acción Nacional por la que se expide la Ley General de Instituciones y Procedimientos Electorales, México, marzo de 2014.

4 Iniciativa con Aval del Grupo Parlamentario del Partido de la Revolución Democrática, con Proyecto de Decreto por el que se expide la Ley General de Instituciones y Procedimientos Electorales, México, marzo de 2014. 
to por México. ${ }^{5}$ En dicho pacto pueden rastrearse los intercambios que hicieron entre sí quienes controlarían al Ejecutivo durante los siguientes seis años, el PRI, con las principales fuerzas de las oposiciones de izquierda, el PRD, y de derecha, el PAN.

La reforma de 2014 concretó las preferencias del PRD y del PAN de restarle poder a los órganos de administración electoral de los estados. En la propuesta original de las oposiciones, contenida incluso en el Pacto por México, se pretendía acabar con las autoridades electorales administrativas locales de las 32 entidades del país, centralizando la conducción y organización de las contiendas en una sola institución nacional, con todas las implicaciones reglamentarias que un cambio así traería consigo. ${ }^{6}$ La justificación de la propuesta centralizadora era el intervencionismo de los gobernadores, a veces a través de la autoridad electoral local, que desequilibraba la cancha de la competencia. Esta propuesta, aceptable al parecer para el presidente de la República, no lo fue para los gobernadores de su partido (y quizá tampoco para los del PAN y del PRD) ni para otros intereses locales, entre los que podrían cuantificarse las crecientes y fuertes burocracias de administración e impartición de justicia electorales locales.

Los partidos aprobaron al final un nuevo modelo de administración nacional que articularía a los órganos locales, debilitados en sus atribuciones y poder, con una nueva autoridad nacional: el INE, que quedó sobrecargado de funciones, pues a las atribuciones que tenía su antecesor inmediato, el IFE, se añadieron otras 73. De acuerdo a la Legipe, le corresponde al Consejo General del INE seleccionar a los integrantes de los consejos generales de los órganos locales de administración electoral, renombrados como los OPLE, mediante un procedimiento totalmente nuevo y seleccionándolos de entre los ciudadanos que cumplan con los requisitos establecidos en la ley. ${ }^{7}$

5 Iniciativa con Proyecto de Decreto por el que se expide la Ley General Electoral, se reforma el Artículo 50, Incisos L) y M) y se adiciona el inciso N) de la Ley Orgánica del Poder Judicial de la Federación, que presentan las Senadoras y los Senadores Integrantes de los Grupos Parlamentarios del Partido Revolucionario Institucional y del Partido Verde Ecologista de México del Senado de la República, México, marzo de 2014.

6 En el acuerdo 90 del Pacto por México se proponía "crear una autoridad electoral de carácter nacional y una legislación única, que se encargue tanto de las elecciones federales, como de las estatales y municipales"; disponible en http://pactopormexico.org.

7 La Legipe (artículo 101) señala que: "1. Para la elección del consejero presidente y los consejeros electorales de los Organismos Públicos Locales, se observará lo siguiente: a) el Consejo General del Instituto emitirá convocatoria pública para cada entidad 
Otra de las novedades incluidas en la Legipe es la facultad de remover a los consejeros electorales de los OPLE por parte del Consejo General del INE bajo ciertas causales, siempre sujetas a múltiples interpretaciones.

Los OPLE, como autoridad administrativa electoral, mantienen facultades como el registro de precandidaturas y candidaturas, el monitoreo de precampañas y campañas que varían en su duración de acuerdo al estado, la regulación en materia de encuestas públicas y resultados preliminares, la entrega de prerrogativas a partidos y contendientes, y la recepción de los paquetes electorales de cada una de las mesas de votación, así como la publicación de resultados preliminares y, una vez concluidos los cómputos distritales, la entrega de constancias de mayoría a los ganadores.

Junto con la nueva distribución de competencias, la reforma dotó al INE de la capacidad de asumir o atraer cualquiera de las funciones administrativas de la autoridad local, así como de delegarle las que la ley le confería, siempre y cuando lo decidiera una mayoría calificada de los integrantes del Consejo General.

federativa que corresponda, en la que deberán considerar expresamente los cargos y periodos a designar, plazos del proceso de designación, órganos ante quienes se deberán inscribir los interesados, requisitos, documentación y el procedimiento a seguir; b) la Comisión de Vinculación con los Organismos Públicos Locales tendrá a su cargo el desarrollo, vigilancia y la conducción del proceso de designación; c) la inscripción y entrega de documentos para el proceso de designación se hará en cada entidad federativa o ante la Secretaría del Consejo General. Para la difusión del proceso y recepción de documentación de los aspirantes, la Comisión se auxiliará de los órganos desconcentrados del Instituto en las treinta y dos entidades federativas; d) la Comisión podrá allegarse de información complementaria para el desarrollo del proceso de designación de las propuestas de integración de cada uno de los consejos locales de los Organismos Públicos Locales. En todos los casos, las personas contenidas en las propuestas deberán cumplir con los requisitos que establece la Constitución y esta Ley; e) la Comisión presentará al Consejo General del Instituto una lista de hasta cinco nombres por vacante en la entidad federativa; f) cuando en el mismo proceso de selección se pretenda cubrir más de una vacante, la Comisión presentará al Consejo General del Instituto una sola lista con los nombres de la totalidad de los candidatos a ocupar todas las vacantes; g) las listas que contengan las propuestas deberán ser comunicadas al Consejo General del Instituto con una anticipación no menor a setenta y dos horas previas a la sesión que corresponda; h) el Consejo General del Instituto designará por mayoría de ocho votos al Consejero Presidente y a los consejeros electorales de los Organismos Públicos Locales, especificando el periodo para el que son designados, e i) el Consejo General del Instituto deberá publicar en el Diario Oficial de la Federación y el equivalente en la entidad federativa, así como comunicar a las autoridades locales dicha designación". 


\section{Integración de los órganos públicos locales electorales}

Conforme a la legislación derivada de la reforma constitucional, los procedimientos para integrar los órganos de administración electoral en las 32 entidades de la República cambiaron.

Anteriormente, las autoridades administrativas electorales en cada estado se integraban replicando, con algunos cambios menores, los procedimientos que se siguen para designar la autoridad administrativa electoral federal, esto es, las cámaras de diputados locales recibían las autopostulaciones de quienes querían integrar el Consejo General, y conforme a los criterios que la ley y/o los reglamentos locales señalaran, nombraban, mediante mayorías calificadas que normalmente implicaban el acuerdo de dos o más partidos, consejeros electorales y consejero presidente, en consejos generales que además diferían en su tamaño, los más chicos con cinco integrantes en 12 estados, y los más grandes de nueve, en Puebla y San Luis Potosí, con remuneraciones a los consejeros que iban de \$16 500 en Nuevo León a \$121 000 en el Distrito Federal, ${ }^{8}$ variaciones en el número de instancias que intervenían en el proceso de su selección, y la existencia legal y real de sus servicios profesionales de carrera, ${ }^{9}$ entre otras variaciones.

Con la nueva normativa, la máxima autoridad administrativa electoral en cada estado sería el Consejo General de los llamados OPLE, integrados en cada una de las 32 entidades por seis consejeros electorales y un presidente. El presidente duraría siete años en su cargo, y los consejeros electorales, seis, pero por única vez y para lograr el escalonamiento de nombramientos, tres consejeros serían designados por seis años y otro tanto igual por tres años. En la selección de los consejeros electorales de cada estado, no intervendrían más las cámaras de diputados locales ni, formalmente, institución alguna de la sociedad civil o de la soberanía estatal. De esta manera, por primera vez en la historia electoral moderna de México, se homologaron los procedimientos para seleccionar a los consejeros electorales locales en todo el país, así como los requisitos que debían cumplir, entre los que destacan el no haber ocupado un cargo de dirección nacional, estatal o municipal en algún partido político en los

8 Simonnet, Carole, "Apuestan partidos al control electoral", Reforma, México, 30 de junio de 2013.

9 Méndez de Hoyos, Irma y Loza Otero, Nicolás, Instituciones electorales, opinión pública y poderes políticos locales en México, México, Flacso México, 2013. 
cuatro años anteriores a la designación, ni haber ocupado ciertos puestos altos en la administración pública, tanto federal como local. ${ }^{10}$

Los interesados en formar parte de estas autoridades electorales deberían autopostularse en respuesta a la convocatoria expedida por el INE, que implicaba cumplir con ciertas características curriculares mínimas, en cuyo caso podrían presentarse después a un examen estandarizado de conocimientos especializados; posteriormente, si quedaban entre los cincuenta mejor calificados en su estado, elaborarían un ensayo también especializado, y de contar con una calificación idónea, pasarían a una evaluación curricular y a una entrevista con los consejeros electorales federales, quienes finalmente harían los nombramientos. En esta secuencia, la única autoridad involucrada fue la administrativa electoral federal, es decir, el INE, sin la intervención de ninguna otra institución federal o local, aunque el propio Instituto decidió delegar en un organismo especializado, el Centro Nacional de Evaluación para la Educación Superior A. C., la elaboración y calificación del examen estandarizado, y en una institución de educación e investigación superior, el Instituto de Investigaciones Jurídicas de la UNAM, la elaboración de las preguntas del ensayo y su calificación.

10 La Legipe, en el artículo 100, establece que "los requisitos para ser consejero electoral local son los siguientes: a) ser ciudadano mexicano por nacimiento, que no adquiera otra nacionalidad, además de estar en pleno goce de sus derechos civiles y políticos; b) estar inscrito en el Registro Federal de Electores y contar con credencial para votar vigente; c) tener más de 30 años de edad al día de la designación; d) poseer al día de la designación, con antigüedad mínima de cinco años, título profesional de nivel licenciatura; e) gozar de buena reputación y no haber sido condenado por delito alguno, salvo que hubiese sido de carácter no intencional o imprudencial; f) ser originario de la entidad federativa correspondiente o contar con una residencia efectiva de por lo menos cinco años anteriores a su designación, salvo el caso de ausencia por servicio público, educativo o de investigación por un tiempo menor de seis meses; g) no haber sido registrado como candidato ni haber desempeñado cargo alguno de elección popular en los cuatro años anteriores a la designación; h) no desempeñar ni haber desempeñado cargo de dirección nacional, estatal o municipal en algún partido político en los cuatro años anteriores a la designación; i) no estar inhabilitado para ejercer cargos públicos en cualquier institución pública federal o local; j) no haberse desempeñado durante los cuatro años previos a la designación como titular de secretaría o dependencia del gabinete legal o ampliado tanto del gobierno de la Federación o como de las entidades federativas, ni subsecretario u oficial mayor en la administración pública de cualquier nivel de gobierno. No ser jefe de Gobierno del Distrito Federal, ni gobernador, ni secretario de Gobierno o su equivalente a nivel local. No ser presidente municipal, síndico o regidor o titular de dependencia de los ayuntamientos, y k) no ser ni haber sido miembro del Servicio Profesional Electoral Nacional durante el último proceso electoral en la entidad". 
Sin embargo, el cambio principal en la naturaleza de la autoridad administrativa electoral local no fue, como se apuntó arriba, en los procedimientos para integrarla ni la duración en el cargo de los consejeros, sino que precisamente estas últimas modificaciones delataban la disminución de atribuciones y competencias de la autoridad administrativa local: los consejos generales de los OPLE serían nombrados por una autoridad federal y no por las cámaras de diputados u otro poder local, lo que formaba parte de una nueva arquitectura institucional en que el gobierno electoral se centralizaba en un sistema jerárquico del INE hacia los OPLE, en donde estos últimos, al conservar su autonomía presupuestal, podrían parecer iguales entre pares frente al INE, cuando no lo eran.

Una de las razones que se esgrimieron, para llevar a cabo esta reforma, fue que los consejeros electorales locales solían designarse bajo la influencia desproporcionada de los gobernadores y/o su partido, pues aunque las mayorías legislativas para los nombramientos implicaban la negociación y acuerdo de al menos una fuerza de oposición, normalmente esta última también era presa del poder del gobernador. Finalmente, se argumentaba que las autoridades administrativas electorales locales eran muy vulnerables a los designios del gobernador, y eso generaba competencias en canchas inclinadas en contra de las oposiciones.

El nuevo procedimiento de designación de consejeros, entonces, tenía como objetivo reducir la influencia de los poderes locales e incluso anularla, al aumentar el papel del mérito y las capacidades, por lo que incluyó, en sus primeras fases, dos filtros basados en la demostración de conocimientos especializados y de capacidades analíticas y argumentativas. Al final, los aspirantes que habían logrado mejores posiciones en el examen estandarizado, y cuyo ensayo se consideró idóneo, pasaron por otros filtros que involucraban diferentes dimensiones. Pero las notas obtenidas en el examen estandarizado y la consideración de idoneidad del ensayo, establecida en una primera evaluación y en algunos casos después de apelación, es decir, en una segunda evaluación, permitían ordenar no sólo a todos los aspirantes en cada estado y a nivel nacional, sino distinguir por estado, género y tipo de consejeros. Estas calificaciones no dicen nada del partidismo de los consejeros - el quid pro quo de la reforma en este terreno-, pero podrían ser buenos indicadores de la capacidad técnica de las nuevas autoridades.

Decretada la reforma, una de las primeras y más urgentes tareas del INE era integrar los consejos generales de los nuevos OPLE en los estados en que habría elecciones en 2015, o cuyos procesos electorales empezaban ese año. Expedida la convocatoria para 18 estados, se presenta- 
ron 3212 aspirantes, 65\% de ellos, hombres. En el Estado de México y el Distrito Federal, concursaron más de 300 aspirantes y en Yucatán, Baja California Sur y Colima, menos de 100.

En el examen estandarizado, la nota promedio de las 50 mejores calificaciones de cada entidad, fue de 8: los aspirantes con más bajas notas fueron, por el promedio del estado, los de Campeche, Yucatán y Baja California Sur, los tres muy cerca pero debajo de 7.5, y los que mejores resultados lograron fueron los de Jalisco con 8.6, del Estado de México con 8.8 y del Distrito Federal con 9.1. Llama la atención que el promedio de las aspirantes mujeres estuvo un punto por debajo respecto a los hombres.

De esta fase del proceso, es decir, el examen estandarizado, podían generarse dos expectativas entre los propios postulantes: por un lado, que los escogidos por el INE para formar el Consejo General del OPLE en su estado tuvieran mejores calificaciones que quienes no fueron seleccionados, y en segundo lugar, que el consejero presidente tuviera una nota más alta que el promedio de sus consejeros. Si la primera expectativa no se cumpliera, podría afirmarse que el OPLE no había sido integrado por los mejores, es decir, los que, de acuerdo al examen, sabían más; si la segunda se cumpliera, el consejero presidente contaría con un elemento adicional a la legalidad de su designación, para construir su liderazgo. En estas 18 entidades, sólo en dos, Chiapas y el Estado de México, los integrantes del Consejo General designado obtuvieron una calificación promedio por debajo de los aspirantes que no resultaron seleccionados, en tanto que en siete, el presidente obtuvo una nota por debajo del promedio de su Consejo.

Después del examen estandarizado, como se apuntó arriba, los 50 mejores evaluados de cada entidad presentaron un ensayo escrito, evaluado en términos de "idóneo"/"no idóneo", cuyo resultado separó a los que podrían pasar a la siguiente fase de los que no, pero no ordenó la capacidad argumentativa de los seleccionados. Sin embargo, quienes redactaron un ensayo considerado "no idóneo", pudieron pedir reconsideración de la nota, y eventualmente modificar el juicio sobre su trabajo. En esta última circunstancia, sólo estuvieron aspirantes de dos estados que terminaron, uno como consejeros presidente, el del Distrito Federal, y otro como consejero electoral, en Guanajuato.

Cubiertas las fases del examen estandarizado y el ensayo, el INE valoró curricularmente y mediante entrevista a los aspirantes. De este último filtro salió la primera propuesta de seis consejeros electorales y uno presidente por estado, que en la mayoría de los casos terminaron siendo los 
designados, aunque en Chiapas, Colima, Tabasco, San Luis Potosí, Morelos y Jalisco, hubo cambios en esa última etapa.

En suma, del conjunto de dimensiones que pueden calibrarse con el proceso, generamos cinco indicadores de calidad en la selección de consejeros, presidente y electorales, de los OPLE: primero, la nota del examen estandarizado, el promedio de sus consejos generales; segundo, que en la misma entidad, la calificación del Consejo superara la de los aspirantes no seleccionados; tercero, que la nota estandarizada del presidente estuviera arriba del promedio del resto de integrantes de su propio Consejo General; cuarto, si había consejeros reprobados en la primera calificación de ensayos, y luego aprobados; y quinto, que la lista de designados coincidiera con la de propuestos.

El primer indicador parte de un examen igual para todos, permite ordenar dentro y fuera del estado, y lo hemos utilizado como una variable de evaluación; los siguientes indicadores son diferencias o excepciones: dos brechas entre notas, una del Consejo y el resto de aspirantes, y otra del consejero presidente y el consejo, y dos excepciones más, primero al evaluarse en segunda ronda los ensayos de aspirantes en la entidad, y la otra si hubiera diferencia entre la primera propuesta y la designación. Entonces, el primer indicador lo hemos usado tal cual en una métrica que podría ir de 0 a 100, pero en los hechos siempre estuvo por encima de 75 y debajo de 95. Los otros indicadores los agregamos en una sola variable a la que llamamos "excepciones y brechas", que si bien podría tomar valores del 0 al 4, cuando todas las brechas y excepciones posibles hubieran ocurrido, en los hechos sólo tomó valores de 0 a 3. En el primer caso, los valores más altos delatan mejor calidad, mientras que en el segundo, los valores más altos indican menor calidad. La relación entre ambos, sin embargo, es débil (véase gráfica 1 en la siguiente página).

Sólo en los estados de Morelos, San Luis Potosí, Tabasco y Chiapas hubo coincidencia en el mal desempeño en ambas evaluaciones, pues allí las brechas y excepciones fueron dos o tres arriba de la media, y el promedio de calificaciones del Consejo General estuvo debajo de la media, que fue de 8.5. Por su parte, Guerrero, Michoacán y Nuevo León ocuparon el cuadrante superior izquierdo de la gráfica, lo que indica buenos resultados en ambos indicadores. No hubo ningún caso de alto promedio en examen estandarizado y mal desempeño en la evaluación por brechas y excepciones, aunque Sonora, Guanajuato, el Estado de México, Jalisco y el Distrito Federal, en este mismo orden ascendente, tuvieron notas altas en el examen estandarizado, y sólo una brecha o excepción, mientras que también con sólo una brecha o excepción, Colima, Querétaro y Cam- 
Esta revista forma parte del acervo de la Biblioteca Jurídica Virtual del Instituto de Investigaciones Jurídicas de la UNAM

peche, ahora en orden descendente, estuvieron debajo de la media en el examen estandarizado.

Gráfica 1. Selección en los OPLE: dos evaluaciones

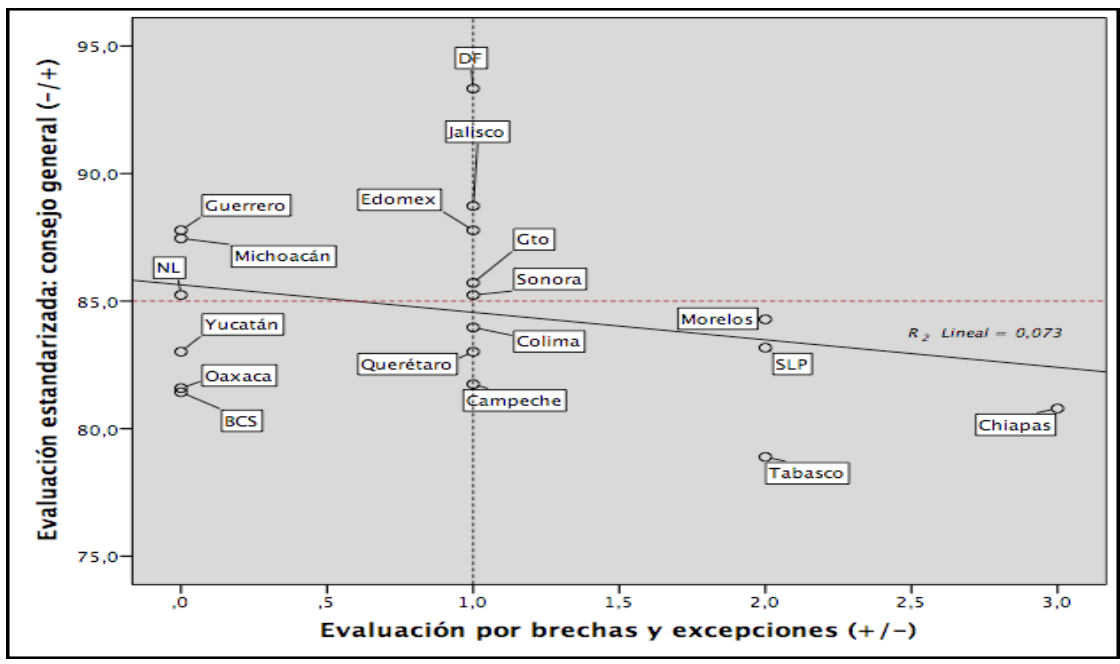

Fuente: Elaboración propia, con datos del proceso de selección de consejeros electorales publicados en el portal del INE, 2014.

IV. El desempeño de los órganos públicos locales electorales: independencia, imparcialidad y procedimientos

Los órganos de administración electoral son órganos directamente encargados de la organización de las elecciones y, en algunos casos, actúan además como garantes del Estado de derecho. ${ }^{11}$ Por ello, su independencia, imparcialidad y profesionalismo son tres atributos centrales que impactan no sólo en su funcionamiento, sino también en la legitimidad del régimen político, sobre todo en contextos de consolidación democrática.

Aunque existen diversas perspectivas, en general se acuerda que la independencia hace referencia a la capacidad de los órganos de administración electoral de no depender de otro órgano, ya sea el Ejecutivo, Legislativo o Judicial, mientras que la imparcialidad consiste en la aplicación de la ley sin sesgos políticos y sin favorecer a alguno de los contendien-

11 López-Pintor, Rafael, Electoral Management Bodies as Institutions of Governance, Bureau Development Policy, Unit Nations Development Programme, 2000. 
tes. ${ }^{12}$ Finalmente, el profesionalismo hace referencia a la capacidad de los miembros de los órganos electorales de organizar una jornada electoral ejemplar, cumpliendo con los más altos estándares técnicos en materias como el registro de electores, la instalación de casillas receptoras del voto, el conteo de votos y la resolución de conflictos.

Bajo el nuevo sistema electoral nacional cabe esperar mínimas variaciones en las legislaciones electorales locales. Como se observa en la tabla 1, en las siguientes páginas, todas las entidades federativas actualizaron sus marcos legales electorales a tiempo para el proceso electoral de 2015. En todos los casos, su normatividad replica, casi textualmente, lo establecido en la Constitución y en la Legipe respecto a la integración, requisitos y remoción de los consejeros electorales de los OPLE. Un elemento que llama la atención es que cada estado conservó un nombre distinto para su ley electoral. Así, para unos es código y para otros es ley. En términos de requisitos, destacan los casos de Baja California Sur, cuya Ley Electoral no hace mención de los requisitos que deben cumplir los consejeros electorales, situación semejante a la de Morelos, donde la ley no lo señala expresamente. Aunque la Legipe es de observancia general en todo el país, la ausencia de reglas claras en cada una de las legislaciones locales abre el espacio para la interpretación y discrecionalidad en la toma de decisiones en estas materias, por parte de los órganos electorales nacionales y locales.

En el caso de la remoción, destacan positivamente los casos de la Ciudad de México y de Nuevo León, en donde las leyes electorales se remiten no sólo a la Legipe y la CPEUM, sino que añaden como causales de remoción algunas conductas tipificadas en las leyes de responsabilidades de los servidores públicos. Con ello se fortalece el sentido de rendición de cuentas de los consejeros electorales locales. En sentido opuesto, se encuentran el Estado de México, Michoacán y Morelos, en los que la ley no habla de la remoción de manera expresa.

En la última columna de dicha tabla 1 se incluyen los resultados del índice de integridad de la ley (IIL) del IP, cuyos resultados están basados en la encuesta a expertos denominada Perceptions of Electoral Integrity Mexico Subnational Study 2015, coordinado a nivel mundial por Pippa

12 Hartlyn, Jonathan et al., "La importancia de la gobernanza electoral y la calidad de las elecciones en América Latina contemporánea”, América Latina Hoy, vol. 51, núm. 1, 2009, pp. 15-40. 
Esta revista forma parte del acervo de la Biblioteca Jurídica Virtual del Instituto de Investigaciones Jurídicas de la UNAM

Norris y su equipo, ${ }^{13}$ y en México, por Irma Méndez y Nicolás Loza. Esta encuesta se aplicó en los estados mexicanos en que hubo elecciones locales, de gobernador y/o diputados, en 2015, siguiendo el procedimiento que este proyecto utilizó para 180 países en el mundo en ese mismo año, incluyendo las elecciones federales en México. Se trata de una evaluación de once dimensiones del proceso electoral, desde su inicio hasta su culminación, a partir del juicio de expertos en cada entidad.

El IIL es una de esas once dimensiones que calibra IP, y sintetiza los valores correspondientes a tres variables: cuando la ley castiga a los partidos pequeños (o es injusta), cuando favorece al partido gobernante y cuando restringe los derechos de los ciudadanos. Según las calificaciones asignadas por los expertos, Chiapas, San Luis Potosí y Yucatán son las entidades con las leyes electorales con menor integridad, o más sesgadas, mientras que Sonora y Jalisco tienen leyes bastante íntegras, es decir, leyes que establecen piso parejo para todos los partidos - y por tanto no son injustas con los partidos pequeños, y tampoco favorecen al partido en el gobierno- - no restringen los derechos ciudadanos.

Tabla 1

\begin{tabular}{|l|l|l|l|l|l|}
\hline \multicolumn{6}{|c|}{ Independencia de los OPLE e integridad de las leyes electorales (IIL) } \\
\hline Ámbito & Leyes & $\begin{array}{l}\text { Integración } \\
\text { en los } \\
\text { OPLE }\end{array}$ & Requisitos & Remoción & IIL \\
\hline Legipe & $\begin{array}{l}\text { Ley General de } \\
\text { Instituciones y } \\
\text { Procedimientos } \\
\text { Electorales } \\
\text { (publicada en } \\
\text { el DOF el 23 de } \\
\text { mayo de 2014) }\end{array}$ & $\begin{array}{l}\text { Artículo 98 } \\
\text { (remite al } \\
\text { artículo } \\
116 \text { de la } \\
\text { CPEUM) }\end{array}$ & Artículo 100 & Artículo 102 & \\
\hline $\begin{array}{l}\text { Baja } \\
\text { California }\end{array}$ & $\begin{array}{l}\text { Ley Electoral } \\
\text { del Estado de } \\
\text { Baja California } \\
\text { Sur } \\
\text { (última reforma } \\
\text { publicada el } \\
\text { 28 de junio de } \\
\text { 2014) }\end{array}$ & Artículo 12 & No hace & Artículo 12 & \\
mención & & & \\
& & & & \\
\end{tabular}

13 Norris, Pippa et al., "The Expert Survey of Perceptions of Electoral Integrity, Mexico Subnational Study 2015”, The Electoral Integrity Project, 2015; disponible en $w w w$. electoralintegrityproject.com. 
Esta revista forma parte del acervo de la Biblioteca Jurídica Virtual del Instituto de Investigaciones Jurídicas de la UNAM

\begin{tabular}{|c|c|c|c|c|c|}
\hline Campeche & $\begin{array}{l}\text { Ley de } \\
\text { Instituciones y } \\
\text { Procedimientos } \\
\text { Electorales } \\
\text { del Estado de } \\
\text { Campeche } \\
\text { (última reforma } \\
\text { publicada el } \\
28 \text { de junio de } \\
2014 \text { ) }\end{array}$ & Artículo 255 & Artículo 261 & Artículo 262 & 61,704 \\
\hline Chiapas & $\begin{array}{l}\text { Código de } \\
\text { Elecciones y } \\
\text { Participación } \\
\text { Ciudadana para } \\
\text { el Estado de } \\
\text { Chiapas } \\
\text { (última reforma } \\
\text { publicada el } \\
30 \text { de junio de } \\
2014 \text { ). }\end{array}$ & Artículo 140 & Artículo 141 & Artículo 142 & 48,36 \\
\hline Colima & $\begin{array}{l}\text { Código } \\
\text { Electoral del } \\
\text { Estado de } \\
\text { Colima } \\
\text { (última reforma } \\
\text { publicada el } \\
28 \text { de junio de } \\
2014 \text { ) }\end{array}$ & Artículo 103 & Artículo 108 & Artículo 110 & 60,54 \\
\hline $\begin{array}{l}\text { Distrito } \\
\text { Federal }\end{array}$ & $\begin{array}{l}\text { Código de } \\
\text { Instituciones y } \\
\text { Procedimientos } \\
\text { Electorales } \\
\text { para el Distrito } \\
\text { Federal } \\
\text { (última reforma } \\
\text { publicada el } 18 \\
\text { de diciembre de } \\
2014 \text { ) }\end{array}$ & Artículo 25 & $\begin{array}{l}\text { Artículo } \\
26,27\end{array}$ & $\begin{array}{l}\text { Artículo } 29 \\
\text { (remite a otras } \\
\text { conductas } \\
\text { establecidas en } \\
\text { la Ley Federal de } \\
\text { Responsabilidades) }\end{array}$ & 67,49 \\
\hline Guanajuato & $\begin{array}{l}\text { Ley de } \\
\text { Instituciones y } \\
\text { Procedimientos } \\
\text { Electorales para } \\
\text { el Estado de } \\
\text { Guanajuato } \\
\text { (última reforma } \\
\text { publicada el } \\
28 \text { de enero de } \\
2016 \text { ) }\end{array}$ & $\begin{array}{l}\text { Artículo } 82 \\
\text { y } 83\end{array}$ & Artículo 83 & Artículo 84 & 62,78 \\
\hline
\end{tabular}


Esta revista forma parte del acervo de la Biblioteca Jurídica Virtual del Instituto de Investigaciones Jurídicas de la UNAM

\begin{tabular}{|c|c|c|c|c|c|}
\hline Guerrero & $\begin{array}{l}\text { Ley de } \\
\text { Instituciones y } \\
\text { Procedimientos } \\
\text { Electorales para } \\
\text { el Estado de } \\
\text { Guerrero } \\
\text { (última reforma } \\
\text { publicada el } \\
29 \text { de junio de } \\
2014 \text { ) }\end{array}$ & Artículo 181 & Artículo 181 & $\begin{array}{l}\text { Artículo } 181 \\
\text { (remite además } \\
\text { a la Constitución } \\
\text { Política local) }\end{array}$ & 64,03 \\
\hline Jalisco & $\begin{array}{l}\text { Código } \\
\text { Electoral y de } \\
\text { Participación } \\
\text { Ciudadana } \\
\text { del Estado de } \\
\text { Jalisco }\end{array}$ & $\begin{array}{l}\text { Artículo } \\
120,121\end{array}$ & Artículo 121 & Artículo 121 & 71,15 \\
\hline México & $\begin{array}{l}\text { Código } \\
\text { Electoral del } \\
\text { Estado de } \\
\text { México } \\
\text { (última reforma } \\
\text { publicada el } \\
28 \text { de junio de } \\
2014 \text { ) }\end{array}$ & Artículo 175 & Artículo 178 & $\begin{array}{l}\text { Artículo } 181 \\
\text { (no lo dice de } \\
\text { manera expresa en } \\
\text { la Ley) }\end{array}$ & 62,70 \\
\hline Michoacán & $\begin{array}{l}\text { Código } \\
\text { Electoral del } \\
\text { Estado de } \\
\text { Michoacán de } \\
\text { Ocampo } \\
\text { (última reforma } \\
\text { publicada el } 4 \\
\text { de febrero de } \\
2015 \text { ) }\end{array}$ & Artículo 32 & Artículo 32 & $\begin{array}{l}\text { No lo dice de } \\
\text { manera expresa en } \\
\text { la Ley }\end{array}$ & 62,70 \\
\hline Morelos & $\begin{array}{l}\text { Código de } \\
\text { Instituciones y } \\
\text { Procedimientos } \\
\text { Electorales para } \\
\text { el Estado de } \\
\text { Morelos } \\
\text { (última reforma } \\
\text { publicada el } \\
30 \text { de junio de } \\
2014 \text { ) }\end{array}$ & Artículo 71 & $\begin{array}{l}\text { No lo dice } \\
\text { de manera } \\
\text { expresa en } \\
\text { la Ley }\end{array}$ & $\begin{array}{l}\text { Artículo } 73 \\
\text { (no lo dice de } \\
\text { manera expresa en } \\
\text { la Ley) }\end{array}$ & 62,08 \\
\hline Nuevo León & $\begin{array}{l}\text { Ley Electoral } \\
\text { para el Estado } \\
\text { de Nuevo León }\end{array}$ & Artículo 88 & Artículo 89 & $\begin{array}{l}\text { Artículo } 90 \\
\text { (la Ley refiere } \\
\text { como causales las } \\
\text { de la Constitución } \\
\text { local y la Ley de } \\
\text { Responsabilidades } \\
\text { de los Servidores } \\
\text { Públicos) }\end{array}$ & 59,20 \\
\hline
\end{tabular}


Esta revista forma parte del acervo de la Biblioteca Jurídica Virtual del Instituto de Investigaciones Jurídicas de la UNAM

\begin{tabular}{|c|c|c|c|c|c|}
\hline Querétaro & $\begin{array}{l}\text { Ley Electoral } \\
\text { del Estado de } \\
\text { Querétaro } \\
\text { (última reforma } \\
\text { publicada el } \\
29 \text { de junio de } \\
2014 \text { ). }\end{array}$ & Artículo 63 & Artículo 62 & Artículo 63 & 61,14 \\
\hline $\begin{array}{l}\text { San Luis } \\
\text { Potosí }\end{array}$ & $\begin{array}{l}\text { Ley Electoral } \\
\text { del Estado de } \\
\text { San Luis Potosí } \\
\text { (última reforma } \\
\text { publicada el } \\
30 \text { de junio de } \\
2014 \text { ) }\end{array}$ & $\begin{array}{l}\text { Artículo 40, } \\
41,42,56\end{array}$ & $\begin{array}{l}\text { Artículo 41, } \\
57 \text { (señala } \\
\text { requisitos } \\
\text { adicionales } \\
\text { para el } \\
\text { resto de los } \\
\text { miembros } \\
\text { del órgano } \\
\text { electoral) }\end{array}$ & Artículo 53, 54, 55 & 50,50 \\
\hline Sonora & $\begin{array}{l}\text { Ley de } \\
\text { Instituciones y } \\
\text { Procedimientos } \\
\text { Electorales para } \\
\text { el Estado de } \\
\text { Sonora } \\
\text { (última reforma } \\
\text { publicada el } \\
7 \text { de julio de } \\
2014 \text { ). }\end{array}$ & Artículo 103 & Artículo 105 & Artículo 117 & 71,37 \\
\hline Tabasco & $\begin{array}{l}\text { Ley Electoral } \\
\text { y de Partidos } \\
\text { Políticos del } \\
\text { Estado de } \\
\text { Tabasco } \\
\text { (última reforma } \\
\text { publicada el } \\
2 \text { de julio de } \\
\text { 2014). }\end{array}$ & Artículo 107 & Artículo 107 & Artículo 109 & 65,96 \\
\hline Yucatán & $\begin{array}{l}\text { Ley de } \\
\text { Instituciones y } \\
\text { Procedimientos } \\
\text { Electorales de } \\
\text { Yucatán } \\
\text { (última reforma } \\
\text { publicada el } \\
28 \text { de junio de } \\
2014 \text { ). }\end{array}$ & $\begin{array}{l}\text { Artículo } \\
110,111, \\
112\end{array}$ & Artículo 112 & $\begin{array}{l}\text { Artículo } 112,114 \\
\text { (señala requisitos } \\
\text { adicionales para } \\
\text { otros miembros del } \\
\text { Instituto Electoral) }\end{array}$ & 58,70 \\
\hline
\end{tabular}

Fuente: Leyes electorales y códigos de los estados.

El IIL está creado por la suma de tres variables: leyes injustas para partidos pequeños, leyes que favorecen al gobernante en turno y leyes que restringen los derechos ciudadanos. Está estandarizado en una escala de 0 a 100 puntos. 
Ahora bien, ¿en qué medida el propósito de aumentar su independencia se logra con estas disposiciones normativas?, ¿en qué medida las nuevas reglas incorporadas en la reforma de 2014 incentivan la imparcialidad de los OPLE?, ¿la exclusión de los congresos locales en la selección de los integrantes de los órganos electorales locales eliminó los sesgos partidistas de sus integrantes?

En términos de la independencia de jure, y de acuerdo a lo mencionado anteriormente, la Legipe y la Constitución Política establecen que los miembros de los OPLE son seleccionados por el Consejo General del INE. Éstos, a su vez, son electos por la Cámara de Diputados a través de un procedimiento que es a la vez meritocrático y político, pues incluye una convocatoria pública, una comisión especial formada por intelectuales destacados y representantes políticos, y la intervención final del pleno de la Cámara, que designa y toma protesta a los consejeros. La naturaleza técnica y política de este proceso de selección determina la naturaleza híbrida del propio órgano electoral nacional.

Los órganos híbridos están conformados por miembros independientes, con méritos profesionales y conocimientos especializados que son seleccionados por un órgano político, aunque también pueden combinar integrantes independientes con aquéllos seleccionados directamente con criterios políticos, como, por ejemplo, los representantes de partidos políticos. ${ }^{14}$ En cualquier caso, la intervención de un órgano político en el proceso de selección (como es la Cámara de Diputados) impacta en alguna medida en el carácter político de los órganos electorales, en este caso del INE. ${ }^{15}$ A nivel subnacional, un estudio conducido por los autores del presente texto confirma el carácter político de los órganos electorales, regidos por la normatividad anterior, según la cual los miembros de los institutos electorales estatales en México en el periodo 2010-2012 eran seleccionados por los congresos locales.

Así pues, y dado el cambio en la normatividad como resultado de la reforma electoral 2014, la pregunta es si el cambio del órgano que selecciona a los miembros de los órganos electorales locales altera efectivamente su naturaleza. La respuesta preliminar es que no es así. En términos generales, el caso mexicano muestra que tanto a nivel federal como local,

14 Foro internacional "La organización electoral en América Latina. Situación, perspectivas y comparación con otras experiencias”, Bogotá, 25 de mayo de 2006, p. 25.

15 Méndez de Hoyos, Irma, Política electoral e independencia en la organización de las elecciones: el Instituto Federal Electoral en las políticas públicas en México, México, El Colegio de México-Porrúa, 2010. 
el carácter meritocrático y técnico de las primeras fases del proceso de selección de los miembros de los órganos electorales no anula la esencia política de las fases finales, lo que implica que la relación entre consejeros electorales y partidos no se trastorna del todo, pues estos últimos retienen el control del proceso de selección, al ser actores con poder de veto en el Consejo General del INE. ${ }^{16}$

Este proceso de selección de los miembros de los OPLE, al que ahora se añaden las propias perspectivas e intereses de los consejeros electorales del INE, genera preguntas sobre los avances en materia de independencia. No sólo no se eliminó, ni de jure ni de facto, la naturaleza política de los órganos electorales locales, sino que se opacó este contenido. Así, vale la pena destacar que antes era claro y transparente el sesgo político de los consejeros, que se distinguía a partir de la nominación de los partidos de los candidatos a consejeros. Frente a ello, bajo la normatividad actual, es dificil saber qué partido "patrocina" a qué consejero. En suma, no sólo no se avanzó en la independencia de los órganos electorales locales, sino que se retrocedió en términos de transparencia del proceso y resultado.

Para examinar el partidismo en los OPLE, se retomaron del IP cuatro variables: una sobre su imparcialidad, otra respecto a la calidad de la información que brinda a los ciudadanos, una más sobre la posibilidad de monitorear su trabajo y la última en torno a su desempeño general. Estas cuatro variables se agregan en un índice sobre la calidad de las autoridades electorales que se expresa en una escala de 0 a 100.

Imparcialidad: las autoridades electorales fueron imparciales (1-5): completamente en desacuerdo, 1. Desacuerdo, 2. Ni de acuerdo ni en desacuerdo, 3. De acuerdo, 4. Completamente de acuerdo, 5. Información a ciudadanos: las autoridades distribuyeron información a los ciudadanos (1-5): completamente en desacuerdo, 1. Desacuerdo, 2. Ni de acuerdo ni en desacuerdo, 3. De acuerdo, 4. completamente de acuerdo, 5. Monitoreo: las autoridades permitieron el escrutinio público de su desempeño (1-5): completamente en desacuerdo, 1. Desacuerdo, 2. Ni de acuerdo ni en desacuerdo, 3. De acuerdo, 4. Completamente de acuerdo, 5. Desempeño: las autoridades electorales se desempeñaron bien (1-5): Completamente en desacuerdo, 1. Desacuerdo, 2. Ni de acuerdo ni en desacuerdo, 3. De acuerdo, 4. Completamente de acuerdo, 5. El indice de autoridad electoral se conforma de las cuatro variables previas y las estandariza a una escala de 0 a 100.

16 Cox, Gary, La coordinación estratégica de los sistemas electorales del mundo. Hacer que los votos cuenten, Barcelona, Gedisa, 2004. 
Esta revista forma parte del acervo de la Biblioteca Jurídica Virtual del Instituto de Investigaciones Jurídicas de la UNAM

Tabla 2

\begin{tabular}{|c|c|c|c|c|c|}
\hline \multicolumn{6}{|c|}{ Imparcialidad y desempeño de los OPLE } \\
\hline Estado & Imparcialidad & $\begin{array}{l}\text { Información } \\
\text { a ciudadanos }\end{array}$ & Monitoreo & Desempeño & $\begin{array}{c}\text { Indice de } \\
\text { autoridad } \\
\text { electoral } \\
(I A U)\end{array}$ \\
\hline $\begin{array}{l}\text { Baja } \\
\text { California } \\
\text { Sur }\end{array}$ & 3.67 & 3.73 & 3.4 & 3.73 & 65.83 \\
\hline Campeche & 3.5 & 3.58 & 3.33 & 3.33 & 60.94 \\
\hline Chiapas & 2.25 & 3.67 & 2.33 & 2.25 & 40.63 \\
\hline Colima & 2.85 & 3.54 & 2.83 & 2.62 & 49.4 \\
\hline $\begin{array}{l}\text { Distrito } \\
\text { Federal }\end{array}$ & 3.33 & 3.57 & 3.38 & 3.3 & 59.63 \\
\hline $\begin{array}{l}\text { Estado de } \\
\text { México }\end{array}$ & 3.06 & 3.5 & 3.38 & 3.5 & 58.98 \\
\hline Guanajuato & 3 & 3.88 & 3.12 & 3 & 56.25 \\
\hline Guerrero & 3.38 & 3.81 & 3.63 & 3.63 & 65.23 \\
\hline Jalisco & 3.52 & 3.78 & 3.74 & 3.52 & 65.97 \\
\hline Michoacán & 3.27 & 3.33 & 3.47 & 3.2 & 57.92 \\
\hline Morelos & 3.38 & 3.92 & 3.54 & 2.92 & 61.06 \\
\hline Nuevo León & 3.38 & 3.58 & 3.57 & 3.42 & 62.47 \\
\hline Querétaro & 3.92 & 3.85 & 3.46 & 3.62 & 67.21 \\
\hline $\begin{array}{l}\text { San Luis } \\
\text { Potosí }\end{array}$ & 3.31 & 3.36 & 3.21 & 3.43 & 57.52 \\
\hline Sonora & 3.6 & 4 & 3.5 & 3.5 & 66.25 \\
\hline Tabasco & 2.3 & 3 & 3.3 & 2.4 & 45.8 \\
\hline Yucatán & 3.5 & 4.2 & 3.78 & 3.8 & 71.16 \\
\hline
\end{tabular}

Fuente: Norris, Pippa et al., The Expert Survey of Perceptions of Electoral Integrity, Mexico Subnational Study 2015, 2015; disponible en www.electoralintegrityproject.com.

En cuanto a la imparcialidad, que es la capacidad de los órganos de administración electoral de tomar decisiones sin favorecer a ninguno de los contendientes, destacan desfavorablemente los estados de Chiapas, Colima y Tabasco, donde se juzga mayoritariamente que los OPLE no lo fueron. La gran mayoría de las entidades se ubican en la categoría intermedia, con calificaciones que sugieren que avanzar en el terreno de la imparcialidad implica ir más allá del nombramiento de aspirantes con formación técnica. El único estado que alcanza una calificación alta 
en imparcialidad es Querétaro, una entidad que alcanza una valoración aprobatoria en muchos de los indicadores contenidos en la encuesta de percepción de la integridad electoral a nivel estatal.

Respecto a la información brindada a los ciudadanos - otra función básica de los órganos electorales - destaca que sólo dos entidades, Yucatán y Sonora, logran una calificación claramente aprobatoria (de 4 o más, en una escala 1-5), mientras que el resto se ubican en el segmento intermedio. Esto sugiere que existe una ciudadanía que exige al mismo tiempo más información, rendición de cuentas y transparencia, lo que se vincula con el monitoreo, que hace referencia a la aceptación de parte de las propias autoridades electorales de la vigilancia pública de su desempeño. En este caso, Chiapas y Colima se ubican como las dos entidades donde los órganos electorales no permitieron la observación pública de su desempeño. También resalta que ningún estado estuvo particularmente abierto al escrutinio, pues sus calificaciones se mantienen en el segmento intermedio (alrededor de 3, en escala de 1 al 5), lo que parece fortalecer la percepción también intermedia de imparcialidad del órgano electoral. En gran medida, el monitoreo público - que es parte de la transparencia - fortalece la imparcialidad de los órganos electorales, pues obliga a sus miembros - los consejeros electorales - a mostrar que son capaces de aplicar la ley sin favorecer a ninguno de los actores políticos.

Por último, en este renglón, el IP solicita a los expertos que juzguen si las autoridades electorales tuvieron un buen desempeño. Los resultados muestran entidades con mal desempeño, con calificaciones de desaprobación cercanas a 2 en una escala 1-5, en donde aparecen de nueva cuenta Chiapas y Colima, seguidos de Tabasco y Morelos, y, por el contrario, estados con calificación aprobatoria y muy por arriba de la media (de 3.2), como Yucatán, Baja California Sur y Querétaro. El resto de las entidades federativas mantienen una valoración intermedia sobre su desempeño, pese a los múltiples esfuerzos para tener mejores órganos de administración electoral.

Finalmente, en la medida general y sintética de las cuatro dimensiones anteriores, el índice de la autoridad electoral, la mayoría de los estados mantienen promedios intermedios; las entidades federativas que tienen las evaluaciones más altas son Yucatán, Querétaro y Sonora; en el extremo opuesto se ubican Chiapas, Colima y Tabasco, con promedios muy bajos.

En términos de profesionalismo, consideramos criterios que califican las funciones más técnicas de los órganos de administración electoral, en que ha habido mayor avance desde las reformas de 1990. Es importante 
mencionar que la reforma de 2014 pretendió elevar de manera particular el profesionalismo de los OPLE, pues incluyó la construcción de un servicio profesional de carrera a nivel nacional. En la medida en que dicho servicio no está aún en operación, no se cuenta con información de sus procesos ni del desempeño de sus miembros. En este sentido, es importante aclarar que las elecciones de 2015 fueron organizadas por los OPLE, renovados parcialmente; si bien se renovaron sus consejos generales, la estructura administrativa permaneció casi sin cambios, y sus miembros no fueron renovados a través de concursos públicos, como lo mandata el nuevo Servicio Profesional Electoral Nacional. Así pues, los indicadores que se utilizan para realizar el análisis del profesionalismo de los OPLE provienen del IP.

La tabla 3 (véase en la siguiente página) muestra la valoración de los expertos para cada entidad federativa respecto a cuatro etapas sustantivas del ciclo electoral: procedimientos electorales, proceso de votación, conteo de votos y resultados, y agrega en la última columna el valor de la integridad de todo el proceso, el PEI, que sintetiza la evaluación de esos once aspectos en un solo indicador que puede ir de 0 a 100, en donde 0 implicaría que no hay integridad electoral en absoluto, y 100 que la hay por completo, aunque el rango observado a nivel subnacional en México fue de poco más de 35 - en el peor caso- a poco menos de 60 - en el mejor-, mientras que las elecciones de Etiopía, con la peor evaluación a nivel internacional en 2015, tuvieron 22 puntos, y las de mayor integridad alcanzaron 86 puntos en Dinamarca y Finlandia. ${ }^{17}$

Procedimiento electoral (imputado). Esta es una escala aditiva creada por la suma de las cuatro variables anteriores (manejo, información de la votación, oficiales justos, elecciones legales) y estandarizada a una escala de 1-100.

Proceso de voto (imputado). Se trata de una escala aditiva conformada por las ocho variables anteriores (violencia, fraudulento, fácil, elección, los servicios postales, los discapacitados, los emigrantes, internet) y normalizada a una escala de $0-100$ puntos.

Conteo de voto (0-100). Se trata de una escala aditiva conformada por las cinco variables anteriores (seguro, retardo, faircount, intlmonitors2, domesticmonitors2) y normalizada a una escala de 0-100 puntos.

Resultados. Se trata de una escala aditiva conformada por las cuatro variables anteriores (challenged2, protestspeace 2 , protestviolent 2 , disputas) y estandarizados a una escala de 0-100 puntos.

17 Norris, Pippa et al., op. cit. 
Esta revista forma parte del acervo de la Biblioteca Jurídica Virtual del Instituto de Investigaciones Jurídicas de la UNAM

Tabla 3

\begin{tabular}{|c|c|c|c|c|c|}
\hline \multicolumn{6}{|c|}{$\begin{array}{c}\text { Profesionalismo, indice de procedimientos electorales (IPP) e indice } \\
\text { general de integridad electoral (PEI) }\end{array}$} \\
\hline Estado & $I P P$ & $\begin{array}{l}\text { Proceso de } \\
\text { votación }\end{array}$ & $\begin{array}{l}\text { Conteo de } \\
\text { votos }\end{array}$ & $\begin{array}{l}\text { Resultados } \\
\text { electorales }\end{array}$ & $P E I$ \\
\hline Baja California Sur & 65.83 & 51.53 & 73.50 & 54.29 & 62.17 \\
\hline Campeche & 61.98 & 44.75 & 70.52 & 47.11 & 64.46 \\
\hline Chiapas & 29.69 & 33.98 & 47.00 & 32.81 & 44.90 \\
\hline Colima & 54.33 & 59.04 & 58.15 & 42.93 & 60.28 \\
\hline Distrito Federal & 62.87 & 46.05 & 71.15 & 50.47 & 57.33 \\
\hline Estado de México & 58.59 & 42.79 & 66.80 & 54.69 & 56.11 \\
\hline Guanajuato & 63.97 & 48.33 & 74.46 & 49.61 & 57.69 \\
\hline Guerrero & 67.19 & 35.69 & 65.03 & 44.92 & 57.70 \\
\hline Jalisco & 65.90 & 47.57 & 69.99 & 66.16 & 61.55 \\
\hline Michoacán & 61.73 & 44.86 & 61.13 & 56.56 & 57.20 \\
\hline Morelos & 43.27 & 40.22 & 57.00 & 47.12 & 53.89 \\
\hline Nuevo León & 65.63 & 48.08 & 71.90 & 64.09 & 56.36 \\
\hline Querétaro & 70.19 & 50.77 & 81.23 & 57.36 & 66.04 \\
\hline San Luis Potosí & 63.17 & 37.24 & 62.71 & 47.92 & 54.81 \\
\hline Sonora & 69.00 & 46.97 & 68.50 & 50.53 & 63.52 \\
\hline Tabasco & 38.30 & 38.57 & 52.57 & 50.68 & 55.30 \\
\hline Yucatán & 66.25 & 44.44 & 77.25 & 51.25 & 62.64 \\
\hline
\end{tabular}

Fuente: Norris, Pippa et al., The expert survey of Perceptions of Electoral Integrity, Mexico Subnational Study 2015, 2015; disponible en www.electoralintegrityproject.com, 2015.

Índice de percepción de integridad electoral (PEI) (imputado): provee un resumen de evaluación en relación a las percepciones que los expertos tienen sobre la atención a estándares internacionales y normas globales.

El índice de procedimientos electorales (IPE) condensa los juicios sobre el manejo de la elección, la información sobre los procedimientos de votación, el juicio sobre si los funcionarios electorales fueron justos y si manejaron la contienda conforme a la ley. Los resultados muestran que hay estados con calificaciones que están muy por debajo de la media, de 59.28 en un rango de 0 a 100, como Chiapas, Tabasco, Colima y Morelos, en donde los procedimientos electorales no cumplen los estándares. En uno de los componentes de esta medida, el que se refiere al buen manejo 
de las elecciones (cuyos resultados particulares no se presentan en la tabla) resaltan los casos extremos también de Chiapas y Morelos, donde los expertos expresan su desacuerdo con el manejo de la elección, a los que se suman Tabasco y Colima. En cuanto a la legalidad de la elección, esto es, su conducción conforme a la ley, figuran de nueva cuenta Chiapas y Tabasco, donde prevalece una percepción negativa, con un alto porcentaje de expertos que comparten que las elecciones no fueron conducidas de acuerdo a la ley.

Así, no parece fortuito que el TEPJF anulara las elecciones de gobernador en Colima debido a irregularidades del proceso electoral, como la intervención directa de funcionarios del gobierno local y la parcialidad del órgano electoral. En Chiapas, por su lado, la Fiscalía Especial para la Atención de Delitos Electorales encontró indicios de fraude electoral, en la medida en que se excluyó del padrón electoral a cientos de ciudadanos que fueron dados de alta sin su conocimiento en la lista de votantes migrantes, con la complicidad u omisión de integrantes del Consejo General del OPLE en el estado. ${ }^{18}$ Esto ocasionó que el Consejo General del INE destituyera a tres de sus miembros e hiciera severos reclamos al resto, que finalmente también fueron destituidos por el TEPJF.

De acuerdo a los resultados del IPE, en 2015, Querétaro y Sonora tuvieron un desempeño destacado, y el resto de las entidades obtuvo promedios justo por arriba de la media, con pocos casos muy desviados hacia abajo, lo que sugiere que los procedimientos electorales son un área con avances sustantivos en materia de integridad electoral subnacional.

La evaluación del proceso de votación incluye numerosos aspectos que tienen que ver con las condiciones en las que los ciudadanos acuden a las urnas. Se incluye la amenaza con violencia en las casillas, los votos fraudulentos, la facilidad para votar, la oferta electoral genuina, el voto postal y apoyos para ciudadanos discapacitados, el voto desde el extranjero y voto por internet. En términos generales, los resultados muestran que existe un amplio margen de mejoras por realizar en este terreno, pues el promedio general en las entidades es bajo, de 44.7, lo que representa una valoración bastante negativa respecto a las garantías que existen para ejercer el derecho al voto en plena libertad. Esto contrasta con el prome-

18 "Quitan fuero a diputado local del PVEM en Chiapas, por presunto fraude electoral"; disponible en http://aristeguinoticias.com/1212/mexico/quitan-el-fuero-a-diputadolocal-del-pvem-en-chiapas-por-presunto-fraude-electoral/; y "Vinculan a consejeros del INE con empresa acusada del fraude electoral en Chiapas", en http://aristeguinoticias. com/1403/mexico/vinculan-a-consejero-del-ine-con-empresa-acusada-del-fraude-electoral-en-chiapas/ (fecha de consultas: 19 de abril de 2016). 
dio general obtenido en el conteo de votos, que es de 66.4, más de 20 puntos por arriba de lo obtenido por el proceso de votación. La medición del conteo de votos incluye garantías de que los votos se cuentan y se cuentan bien, esto al considerar que las urnas estén seguras, los resultados sean anunciados en tiempo, los votos estén bien contados, y los observadores tanto nacionales e internacionales cuenten con garantías para realizar su tarea de monitoreo. En general, los resultados sugieren que existen importantes logros en materia de los procedimientos básicos de elecciones democráticas, incluido el conteo de votos, pero aún falta mucho para garantizar una mayor calidad en dichos procedimientos.

Otra etapa del ciclo electoral que muestra serios retos es la de los resultados de la elección. La evaluación de resultados que se muestra en la tabla 3 incluye variables relativas a la conducta o reacción de los actores políticos frente a los resultados, lo que involucra al proceso de legitimación de los resultados. Así pues, se incluye si los partidos o candidatos desconocen o no los resultados, si se registran protestas pacíficas o violentas, y si las disputas generadas por los resultados se dirimen a través de los canales legales o no. El promedio general en las entidades es de 51 puntos, lo que sugiere que, en términos generales, existe una valoración negativa de las condiciones en que se producen los resultados electorales, lo que genera serios déficits de legitimidad política.

\section{V. Índice de integridad electoral y selección de consejeros electorales locales}

En la literatura especializada sobre calidad de las elecciones, suele afirmarse que de las muchas variables de las que depende la calidad de una elección, quizá la calidad del instituto encargado de organizarlas y arbitrar entre los contendientes sea el factor de mayor importancia y de efecto inmediato, sobre el que además es posible incidir en relativamente poco tiempo. ${ }^{19}$ Sin embargo, es difícil calibrar una y otra variables: la calidad de una elección no se deduce, simplemente, del número de impugnaciones jurídicas o políticas; no, al menos, cuando impugnar se ha convertido en una estrategia dominante de los competidores; la aceptación de los resultados por parte del perdedor tampoco parece ser un indicador confiable, pues descalificarlos, acatarlos bajo protesta es una extensión de la estrategia de impugnar. Al trasladarnos a la calificación del órgano encargado de las elecciones, también enfrentamos problemas, primero porque

19 Hartlyn, Jonathan et al., op. cit. 
impugnar su desempeño, sobre todo cuando da a conocer los resultados, expresa precisamente la estrategia antes referida; por su parte, si bien sus características institucionales generales hacen diferencias relevantes entre países (independencia, partidismo, autonomía, profesionalismo, recursos, etcétera), al tratarse de autoridades administrativas subnacionales en México, no hay variaciones en todos estos renglones, sino sólo en algunos (que ya tratamos anteriormente), así como en la ejecución de algunos principios y reglas, como la profesionalización o el número de partidos que podrían dominar el Consejo General. Sobre las dificultades de lograr buenos indicadores para ambos aspectos, escribimos en otra ocasión, ${ }^{20} \mathrm{y}$ ahora ofrecemos soluciones diferentes.

Por un lado, para estimar la calidad de la elección en cada estado, usamos el PEI de IP, es decir, el indicador de integridad general. En las 17 elecciones subnacionales de México en 2015, la mayor integridad la lograron los estados de Querétaro, Jalisco, Baja California Sur, Sonora, Yucatán y el Distrito Federal, muy cerca o por arriba de los 55 puntos; en tanto que los de menor integridad fueron Chiapas, con 37 puntos, Tabasco con 47, y el Estado de México, Morelos y San Luis Potosí con no más de 50 puntos. Entre los de menor y mayor puntaje, aparecen en orden ascendente Michoacán, Nuevo León, Guerrero, Colima, Guanajuato y Campeche. ¿Este orden se relacionó sistemáticamente con los puntajes que alcanzaron los consejeros electorales en el proceso de selección del Consejo General de los OPLE un año antes? ¿Se relacionó con el número de excepciones y brechas? En el primer caso, la respuesta es no, y sí, en el segundo.

Aunque dos entidades, Jalisco y el Distrito Federal, con calificaciones promedio altas de sus consejos generales en el proceso de selección también se colocaron arriba de la media de integridad, y los dos peor evaluados, Tabasco y Chiapas, exhiben las calificaciones más bajas del examen estandarizado, las demás entidades se dispersan en torno a los valores medianos de cada distribución sin mayor regularidad, lo que puede apreciarse gráficamente y por el bajo coeficiente de correlación (véase gráfica 2 en la siguiente página).

Cuando relacionamos la integridad de las elecciones con la evaluación del proceso de selección de consejeros y la medición de brechas y excepciones, encontramos una relación inversa, fuerte y significativa; es decir, que en aquellos estados en donde hubo más excepciones (ensayos aprobados en segunda vuelta; designados diferentes a los propues-

20 Méndez de Hoyos, Irma y Loza Otero, Nicolás, op. cit. 
Esta revista forma parte del acervo de la Biblioteca Jurídica Virtual del Instituto de Investigaciones Jurídicas de la UNAM

tos) o la brecha de calificaciones fue mayor (aspirantes>consejeros; consejeros>presidente): la calidad de la elección fue menor.

\section{Gráfica 2. Integridad electoral y evaluación de los OPLE por examen estandarizado}

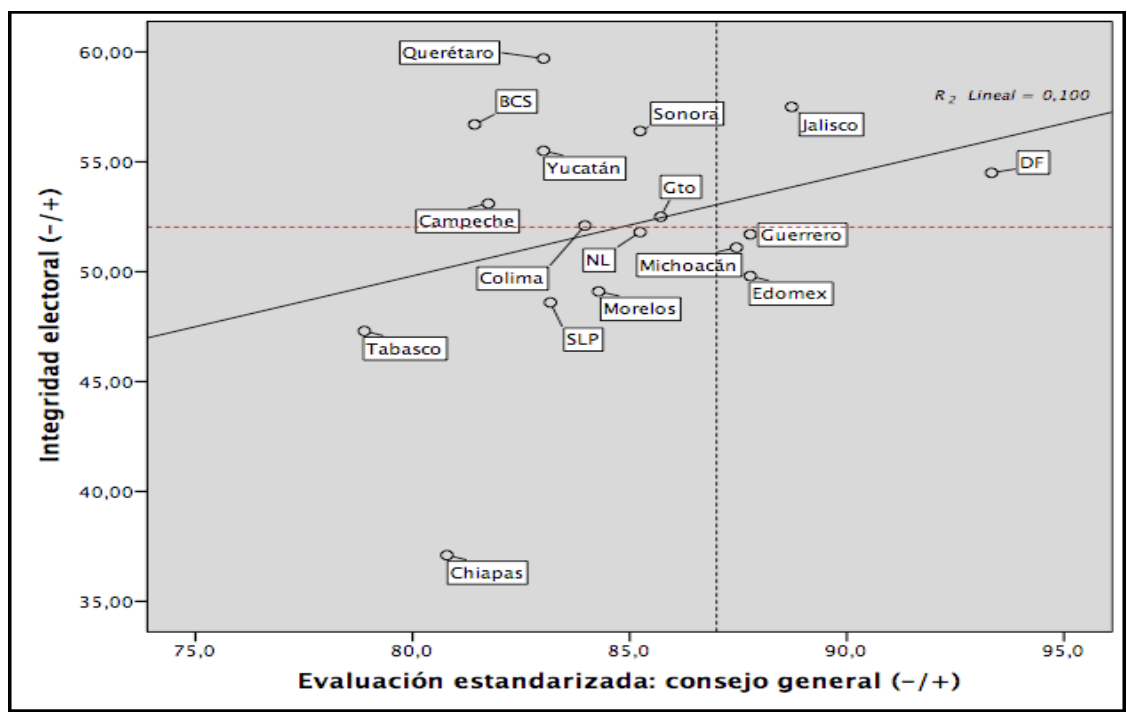

FuENTE: Elaboración propia, con datos del proceso de selección de consejeros electorales publicados en el portal del INE, 2014.

Chiapas registró tres puntos en esta medición, en este caso, dos brechas y una excepción, y tuvo, como se ha reiterado, la menor integridad registrada, mientras que los cinco estados en que no se tuvo noticia ni de brechas ni de excepciones se sitúan también por arriba de la mediana de integridad. ¿Quiere decir que las deficiencias en integridad electoral fueron ocasionadas por problemas de selección de consejeros de los OPLE, observada esta última no por las calificaciones promedio del Consejo General en el examen estandarizado, sino por la presencia de excepciones y brechas? De ninguna manera puede afirmarse que así haya sido, pero la concomitancia entre ambas variables en estas 17 elecciones proporciona suficiente evidencia como para sugerir que debe investigarse con más observaciones y modelos adecuados este problema (gráfica 3). 
Esta revista forma parte del acervo de la Biblioteca Jurídica Virtual del Instituto de Investigaciones Jurídicas de la UNAM

Gráfica 3. Integridad electoral y selección de los OPLE por brechas y excepciones

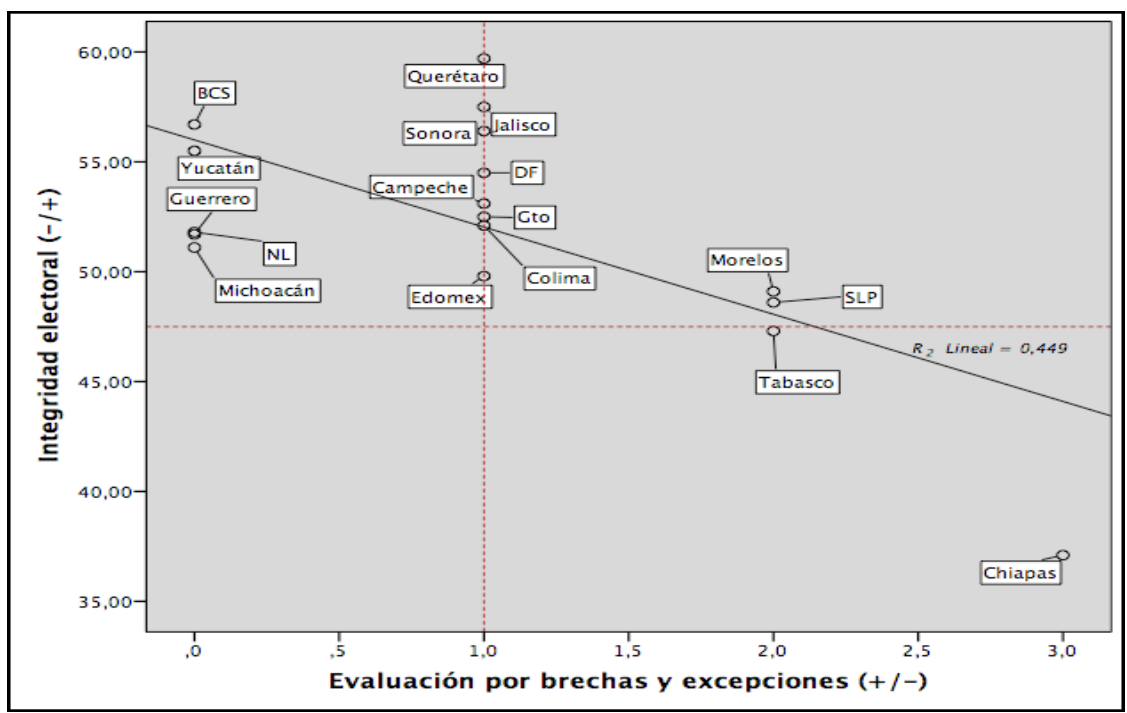

FuENTE: Elaboración propia, con datos del proceso de selección de consejeros electorales publicados en el portal del INE, 2014.

\section{Conclusiones}

Existe un amplio consenso sobre el papel de las reformas electorales federales y locales en el proceso de transición a la democracia en México y, en particular, respecto a la labor de los órganos electorales creados entre 1990 y 1996. El IFE y, posteriormente, los institutos electorales estatales permitieron el tránsito de elecciones manipuladas y ampliamente cuestionadas a la organización de elecciones democráticas. ${ }^{21}$

La reforma electoral de 2014 representa la culminación de un amplio esfuerzo por consolidar un modelo de órganos electorales híbridos, crea-

21 Woldenberg, José, Después de la transición: gobernabilidad, espacio público y derechos, México, Aguilar, León y Cal Editores, 2006; Becerra, Ricardo et al., La mecánica del cambio político en México: elecciones, partidos y reformas, México, Cal y Arena, 2000; Merino, Mauricio, La transición votada. Crítica a la interpretación del cambio político en México, México, FCE, 2003; Magaloni, Beatriz, Voting for Autocracy: Hegemonic Party Survival and its Demise in Mexico, New York, Cambridge University Press, 2006; Méndez de Hoyos, Irma, Transición a la democracia en México. Competencia partidista y reformas electorales 1977-2003, México, Fontamara, 2006; Salazar, Luis C. (coord.), México 2000. Alternancia y transición a la democracia, México, Cal y Arena, 2001. 
dos bajo el paradigma de la independencia, la imparcialidad y el profesionalismo, pero que mezcla elementos técnicos y profesionales con filtros políticos. El modelo mexicano, como se le ha llamado, ha cambiado poco a pesar de la creciente desconfianza que revelan las encuestas de opinión hacia los órganos electorales, tanto locales como federales, y hacia las elecciones en general. La evidencia presentada en el texto muestra que si bien hay avances limitados en materia de organización electoral, y en particular respecto del proceso de votación, lo que revela mayor profesionalismo, se mantienen y en muchos casos se incrementan los cuestionamientos a su imparcialidad, la gran deuda de las reformas electorales en México.

Es importante reconocer que, si bien bajo el nuevo procedimiento para elegir consejeros de los OPLE hay una mayor exigencia de conocimientos técnicos, el sesgo político introducido al final del proceso genera, al parecer, resultados no deseados en la calidad e integridad electoral. Así pues, uno de los hallazgos relevantes, presentados en este trabajo, muestra que existe una relación entre la medida en que se advierten excepciones en las evaluaciones realizadas a los candidatos a consejeros electorales y la integridad de las elecciones locales celebradas en 2015. Pareciera que los criterios políticos que sesgan o desdeñan, en algunos casos, el mérito técnico generan al final canchas desiguales, o no parejas, lo que impacta negativamente en la calidad de las elecciones en su conjunto.

\section{Fuentes consultadas}

BeCerra, Ricardo et al., La mecánica del cambio político en México: elecciones, partidos y reformas, México, Cal y Arena, 2000.

Bowler, Shaun y Donovan, Todd, The Limits of Electoral Reform, Oxford, Oxford University Press, 2013.

Cox, Gary, La coordinación estratégica de los sistemas electorales del mundo. Hacer que los votos cuenten, Barcelona, Gedisa, 2004.

Foro internacional "La organización electoral en América Latina. Situación, perspectivas y comparación con otras experiencias”, Bogotá, 25 de mayo de 2006, p. 25.

HARTLYN, Jonathan et al., "La importancia de la gobernanza electoral y la calidad de las elecciones en América Latina contemporánea", América Latina Hoy, vol. 51, núm. 1, 2009, pp. 15-40.

Iniciativa con Aval de Grupo Parlamentario del Partido Acción Nacional por la que se expide la Ley General de Instituciones y Procedimientos Electorales, México, marzo de 2014. 
Iniciativa con Aval del Grupo Parlamentario del Partido de la Revolución Democrática, con Proyecto de Decreto por el que se expide la Ley General de Instituciones y Procedimientos Electorales, México, marzo de 2014.

Iniciativa con Proyecto de Decreto por el que se expide la Ley General Electoral, se reforma el Artículo 50, Incisos L) y M) y se adiciona el Inciso N) de la Ley Orgánica del Poder Judicial de la Federación, que presentan las Senadoras y los Senadores Integrantes de los Grupos Parlamentarios del Partido Revolucionario Institucional y del Partido Verde Ecologista de México del Senado de la República, México, marzo de 2014.

Ley General de Instituciones y Procedimientos Electorales, disponible en: http://norma.ife.org.mx/documents/27912/310245/2014_LGIPE. pdf/5201e72c-0080-4acb-b933-5137ef1c0c86.

LóPEZ-Pintor, RAFAeL, Electoral Management Bodies as Institutions of Governance, Bureau Development Policy, Unit Nations Development Programme, 2000.

Magaloni, Beatriz, Voting for Autocracy: Hegemonic Party Survival and its Demise in Mexico, Nueva York, Cambridge University Press, 2006.

Méndez de Hoyos, Irma, Transición a la democracia en México. Competencia partidista y reformas electorales 1977-2003, México, Fontamara, 2006.

-_- , Política electoral e independencia en la organización de las elecciones: el Instituto Federal Electoral en las políticas públicas en México, México, El Colegio de México-Porrúa, 2010.

- - - y Loza Otero, Nicolás, Instituciones electorales, opinión pública y poderes políticos locales en México, México, Flacso México, 2013.

Merino, Mauricio, La transición votada. Crítica a la interpretación del cambio político en México, México, FCE, 2003.

Norris, Pippa et al., The Expert Survey of Perceptions of Electoral Integrity, Mexico Subnational Study 2015, The Electoral Integrity Project, 2015; disponible en www.electoralintegrityproject.com.

Pacto por México; disponible en http://pactopormexico.org.

"Quitan fuero a diputado local del PVEM en Chiapas, por presunto fraude electoral"; disponible en http://aristeguinoticias.com/1212/mexico/ quitan-el-fuero-a-diputado-local-del-pvem-en-chiapas-por-presuntofraude-electoral (fecha de consulta: 19 de abril de 2016).

Salazar, Luis C. (coord.), México 2000. Alternancia y transición a la democracia, México, Cal y Arena, 2001. 
Esta revista forma parte del acervo de la Biblioteca Jurídica Virtual del Instituto de Investigaciones Jurídicas de la UNAM

Simonnet, Carole, "Apuestan partidos al control electoral", Reforma, México, 30 de junio de 2013.

"Vinculan a consejeros del INE con empresa acusada del fraude electoral en Chiapas" en http://aristeguinoticias.com/1403/mexico/vinculan-aconsejero-del-ine-con-empresa-acusada-del-fraude-electoral-en-chiapas (fecha de consulta: 19 de abril de 2016).

Woldenberg, José, Después de la transición: gobernabilidad, espacio público y derechos, México, Aguilar, León y Cal Editores, 2006. 